\title{
Endoscopic submucosal dissection for localized amyloidosis of the sigmoid colon
}

Amyloidosis is a rare disease caused by the extracellular deposition of amyloid, which results from the self-assembly of various precursor proteins with a highly ordered and abnormal cross- $\beta$ sheet structure [1,2].

Gastrointestinal amyloidosis sometimes leads to ulcer, gastrointestinal bleeding, and intestinal obstruction [3,4]. Endoscopic mucosal resection (EMR) has been reported as a treatment for localized amyloidosis of the colon which was causing bloody stool [5].

An 82-year-old man underwent colonoscopy for follow-up after colorectal polypectomy, and a submucosal tumor (SMT)-like lesion was detected in the sigmoid colon. The lesion was yellowishwhite and appeared to be slightly hard ( Fig. 1 a). It was covered by nonneo- plastic epithelium with slight fold stretching. Magnified chromoendoscopy revealed an elongated type I pit, compatible with SMT, and its surface structure appeared to be stretched by the submu-

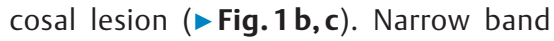
imaging (NBI) with magnification revealed a heterogeneous vessel pattern with uneven caliber and a slightly irregular surface pattern ( $\mathbf{F i g . 1 d}$ ). On endoscopic ultrasound (EUS), the lesion was hypoechoic with thickening in the third layer, and the border of the lesion was indistinct and partially mosaic-like (> Fig.1e). Biopsy specimens revealed colonic amyloid deposit. A systematic search including upper gastrointestinal endoscopy and small-bowel capsule endoscopy was performed, but no other lesion was detected.
If the amyloid lesion were to increase in size, the patient would be at risk of bowel obstruction and bleeding, so we performed an endoscopic submucosal dissection (ESD) for this SMT ( $\triangleright$ Video 1 ). Histopathological examination showed deposition of eosinophilic unstructured tissue from the mucosa to the submucosa, and orange staining with Congo red staining and amyloid deposition was observed ( $\mathbf{F i g} \mathbf{2} \mathbf{a}, \mathbf{b}$ ). Follow-up colonoscopy revealed a scar after ESD but no recurrence was detected.

In conclusion, curative resection may be performed for localized amyloidosis of the colon, and endoscopic treatment could be one option for localized amyloidosis.

Endoscopy_UCTN_Code_CCL_1AD_2A

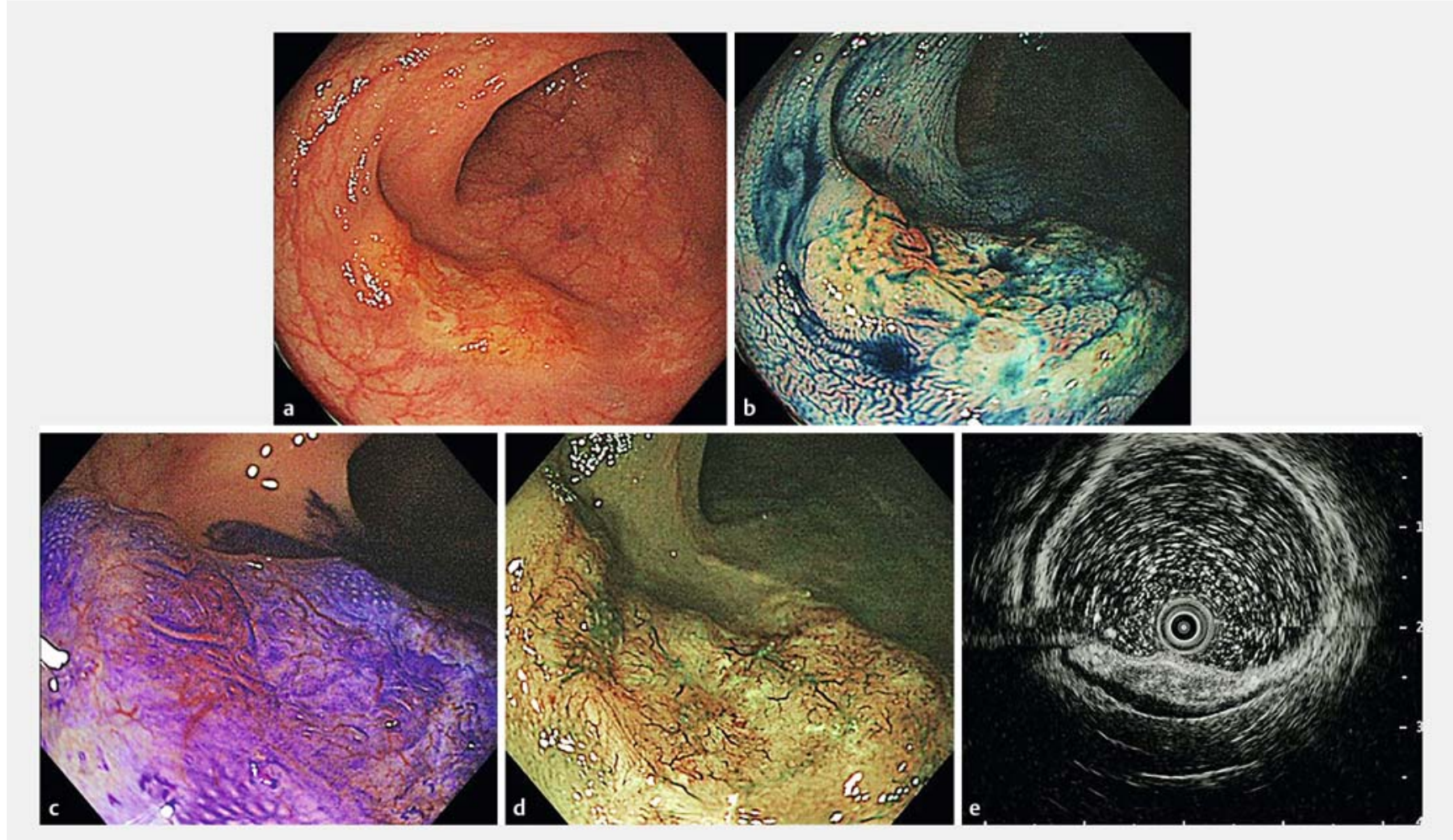

- Fig. 1 Endoscopic images show this lesion as flat, yellowish-white, and apparently slightly hard. a White light image. b Chromoendoscopy with indigo carmine dye spray. c Chromoendoscopy with crystal violet reveals only an elongated type I pit. $\mathbf{d}$ Narrow band imaging (NBI) shows a Japan NBI Expert Team (JNET) type 1 lesion. e Endoscopic ultrasound shows that the lesion is hypoechoic with thickening in the third layer, and the border of the lesion is indistinct and partially mosaic-like. 

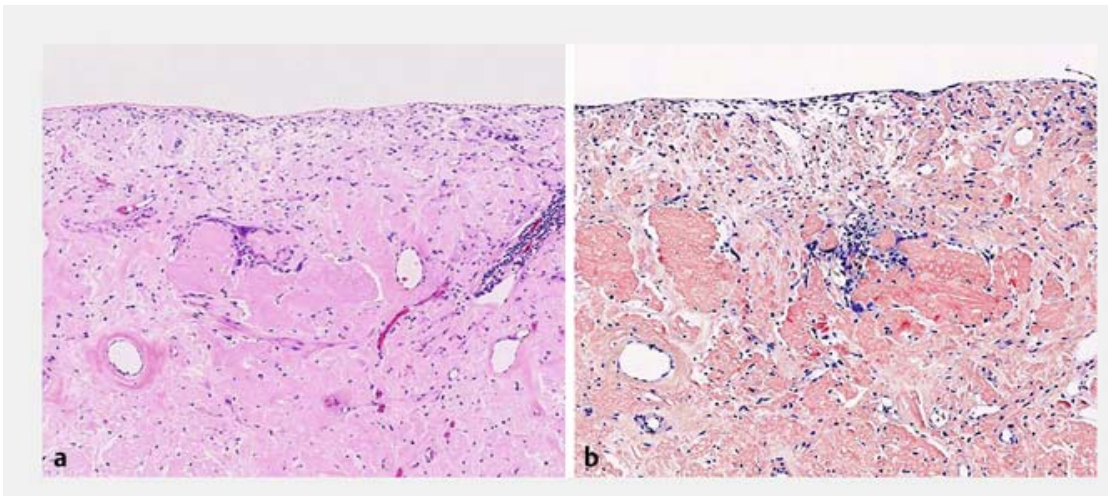

- Fig. 2 Histopathologic findings. a Hematoxylin and eosin staining shows deposition of eosinophilic unstructured tissue from the mucosa to the submucosa. $\mathbf{b}$ Congo red staining reveals amyloid deposition with orange coloring of eosinophilic unstructured tissue deposits from the mucosa to the submucosa.
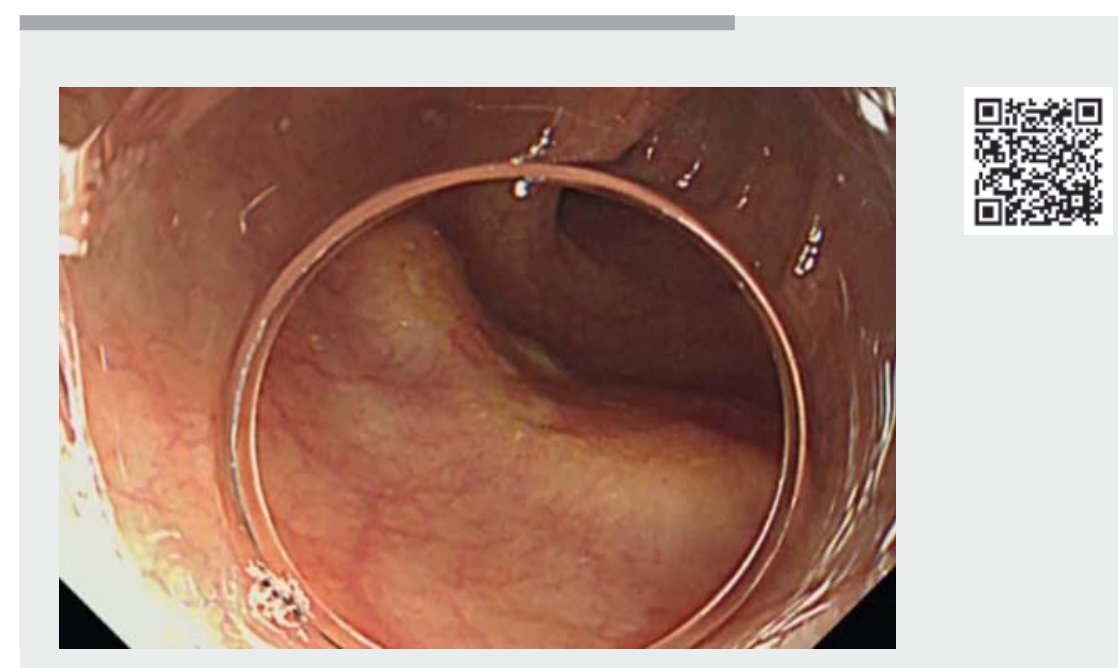

$\checkmark$ Video 1 Endoscopic submucosal dissection for localized amyloidosis of the sigmoid colon.

\section{Funding}

This work was supported in part by The National Cancer Center Research and Development Fund (29-A-13 and 2020-A-12). 29-A-13 and 2020-A-12

\section{Competing interests}

The authors declare that they have no conflict of interest.
The authors

Kei Nakazawa ${ }^{1,2}$, Yutaka Saito', Shigetaka Yoshinaga' ${ }^{1}$, Shigeki Sekine ${ }^{3}$, Kazuhide Higuchi $^{2}$

1 Endoscopy Division, National Cancer Center Hospital, Tokyo, Japan

2 Second Department of Internal Medicine, Osaka Medical College, Osaka, Japan

3 Pathology Division, National Cancer Center Hospital, Tokyo, Japan
Corresponding author

\section{Yutaka Saito, MD, PhD}

5-1-1 Tsukiji, Chuo-ku, Tokyo 104-0045, Japan

ytsaito@ncc.go.jp

\section{References}

[1] Lachmann HJ, Hawkins PN. Systemic amyloidosis. Curr Opin Pharmacol 2006; 6: 214220

[2] Merlini G. Systemic amyloidosis: are we moving ahead? Neth J Med 2004; 62: 104105

[3] Matsui H, Kato T, Inoue G et al. Amyloidosis localized in the sigmoid colon. J Gastroenterol 1996; 31: 607-611

[4] Racanelli V, D’Amore FP. Localized AL amyloidosis of the colon and clinical features of intestinal obstruction. A case report. Ann Ital Med Int 1999; 14: 58-60

[5] Ogasawara N, Kitagawa W, Obayashi K et al. Solitary amyloidosis of the sigmoid colon featuring submucosal tumor caused hematochezia. Intern Med 2013; 52: 2523-2527

\section{Bibliography}

Endoscopy 2022; 54: E5-E6

DOI 10.1055/a-1346-8645

ISSN 0013-726X

published online 16.2 .2021

(c) 2021. Thieme. All rights reserved.

Georg Thieme Verlag KG, Rüdigerstraße 14, 70469 Stuttgart, Germany

\section{ENDOSCOPY E-VIDEOS \\ https://eref.thieme.de/e-videos}

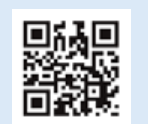

Endoscopy E-Videos is a free access online section, reporting on interesting cases and new techniques in gastroenterological endoscopy. All papers include a high quality video and all contributions are freely accessible online.

This section has its own submission website at https://mc.manuscriptcentral.com/e-videos 